\title{
MICRONUCLEI - AS A BIOMARKER OF GENOTOXICITY IN AUTOMOBILE MECHANICS OF WESTERN MAHARASHTRA
}

\author{
SMITA V PATIL ${ }^{1 *}$, SUMANGALA PATIL ${ }^{1}$, SAMPADA KANITKAR ${ }^{2}$ \\ ${ }^{1}$ Department of Physiology, BLDE University's, Shri B. M. Patil Medical College, Bijapur, Karnataka, India. ${ }^{2}$ Department of Oral Pathology, \\ Bharati Vidyapeeth University, Dental College and Hospital, Sangli, Maharashtra, India. Email: mailmesmita.patil@rediffmail.com
}

Received: 10 October 2017, Revised and Accepted: 25 May 2018

\section{ABSTRACT}

Objective: The aim of this study was to assess the potential cytogenetic damage associated with occupational exposure to polycyclic aromatic hydrocarbons (PAHs) among automobile mechanics (AMs) using micronuclei (MNs) and other nuclear abnormalities (NAs) such as binucleate cell $(\mathrm{BN})$, karyorrhexis (KR), and karyolysis (KL) as biomarkers of genotoxicity.

Methods: The study was conducted on 60 AMs between age group of 20-40 years who were working in automobile garages for more than 1 year from western Maharashtra, and 60 healthy males with same socioeconomic status were chosen as controls. AMs were divided into three groups based on their duration of exposure, i.e. 1-5 years, 6-10 years, and more than 11 years. The exfoliated buccal cells were obtained and fixed with methanol for $10 \mathrm{~min}$. Then, air-dried and stained it with Giemsa stain. Statistical analysis was done using unpaired t-test for two groups and one-way ANOVA for multiple groups of exposures.

Results: The mean values of MN, BN, KR, and KL in AMs (8.20, 13.57, 16.70, and 22.10, respectively) are significantly increased as compared to controls $(5.10,8.82,12.30$, and 16.12, respectively). As the year of exposure increased, the mean values of MN and other NAs were significantly increased in AMs $(\mathrm{p}<0.05)$.

Conclusion: MN and other NAs reflect genetic changes and events associated with carcinogenesis. Therefore, the results of this study indicate that AMs exposed to PAHs are under risk of significant cytogenetic damage. Therefore, it is important to provide and to create better awareness of occupational hazards among these workers to promote occupational safety.

Keywords: Micronuclei, Binucleate cell, Karyorrhexis, Karyolysis, Genotoxicity.

(C) 2018 The Authors. Published by Innovare Academic Sciences Pvt Ltd. This is an open access article under the CC BY license (http://creativecommons. org/licenses/by/4. 0/) DOI: http://dx.doi.org/10.22159/ajpcr.2018.v11i8.23005

\section{INTRODUCTION}

To live in the $21^{\text {st }}$ century means to live in a toxic world, where daily we get exposed to large number of toxic substances. Millions of workers in a variety of occupational settings have the potential to get exposed to toxic substances. They can be present in the form of gases, vapors, fumes, and particles [1]. Automobile mechanics (AMs), because of their occupation get exposed to toxic substances, which include polycyclic aromatic hydrocarbons (PAHs), which are found in petroleum products. PAHs are a major class of environmentally hazardous organic compounds due to their known or suspected carcinogenicity $[2,3]$ and are known to be toxic.

Micronuclei (MNs) originate from chromosome fragments or whole chromosomes that lag behind at anaphase during nuclear division [4]. Biomarkers of genotoxicity (MN) have received a considerable interest as tools for detecting human genotoxic exposure to various chemical carcinogens. Different types of bioassays have been widely used for assessing the genotoxic, mutagenic, and carcinogenic potencies of different substances. Biomarkers have been defined by the National Academy of Sciences (USA) as an alteration in cellular or biochemical components, processes, structures, or functions that are measurable in a biological system or sample. The traditional classification of biomarkers is of three main categories - biomarkers of exposure, effect, and susceptibility - depending on their toxicological significance [5]. Cytogenetic biomarkers are the most frequently used end points in human biomonitoring studies and are used extensively to assess the impact of environmental, occupational, and medical factors on genomic stability [6]. The present study incorporates all three categories of biomarkers to promote occupational safety.

MN assay is one of the most sensitive markers for detecting DNA damage and has been used to investigate genotoxicity of a variety of chemicals. Exposure to gasoline vapors is classified by the International Agency for Research on Cancer as possibly carcinogenic to humans, mainly on the basis of the well-established carcinogenicity of some components such as benzene [7]. Benzene is proven to be carcinogenic in nature. Several studies have shown that benzene can induce various forms of genetic damage including chromosome aberrations, sister chromatid exchanges, MNs formation, and DNA damage [8].

In western Maharashtra, automobile garages are located on the road, and workers at the garages have a higher opportunity for exposure. AMs are engaged in doing routine maintenance and repairing the automotive vehicles. They are commonly exposed to PAH due to sucking of petrol or diesel through tube from the vehicle tank, while repairing the vehicles. They also often wash vehicle parts with petrol without wearing gloves. They are usually negligent regarding use of protective measures. Therefore, the occupational exposure to PAHs and other derivatives may possess genotoxic risk. Occupational exposure to carcinogens is of great public health concern.

Regeneration of cell is dependent on the number and division rate of the proliferating (basal) cells, their genomic stability, and their propensity 
for cell death. These events can be studied in the buccal mucosa (BM), which is an easily accessible tissue for sampling cells in a minimally invasive manner and does not cause undue stress to study participants. Buccal epithelial cell is an indication of the regenerative capacity of the tissue that is why we collect sample from BM.

In the light of the above discussion, we applied MNs and other nuclear abnormalities (NAs) as a biomarker of genotoxicity in exfoliated buccal cells of AMs of western Maharashtra.

\section{METHODS}

After the approval by institutional ethical committee, a crosssectional study was carried out on 60 automobile workers of western Maharashtra (Sangli, Satara, and Kolhapur district) with age group of 20-40 years. They were further divided into three groups depending on their duration of exposure as Group I (1-5 years), Group II (510 years), and Group III (more than 10 years). Sixty control participants were chosen from paramedical staff of the same age, gender, and socioeconomic status from Bharati Vidyapeeth Medical and Dental College and Hospital Sangli. Workers were evaluated as per standard pro forma, which included a questionnaire regarding health status. Randomly selected 60 automobile workers were eligible to whom the experimental protocol was explained, and written informed consent was obtained from them. Workers with $<1$ year exposure and tobacco/ mawa/gutkha chewers were excluded from the study.

Before buccal cell collection, the participants' mouth was rinsed thoroughly with water to remove any unwanted debris. The exfoliated cells of the BM were obtained by a sterile wooden spatula. For each individual, the slides were prepared in triplicate by smearing the cells onto pre-cleaned slides. The slides were then air-dried and fixed with methanol for $10 \mathrm{~min}$. Then, air-dried again and stained it with Giemsa (Biolab diagnostic Pvt., Ltd.) stain for 15-20 min.

\section{Scoring method}

Slides were evaluated using classification for NAs by Tolbert et al. [9]. Frequencies of MNs, binucleation, karyorrhexis (KR), and karyolysis (KL) in exfoliated 1000 cells were scored per slide. Nuclei less than one-third the diameter of the main nucleus were determined as MNs (Fig. 1b). Cells with two nuclei were considered as binucleate cells (BNs) (Fig. 1c). Nuclei fragmented into irregular pieces were scored as KR (Fig. 1d). Nuclear dissolution, ghost-like image of the nucleus remains, was evaluated as KL (Fig. 1e).

Results were presented as mean \pm standard deviation (SD). Unpaired t-test and ANOVA test were used to find the significance of study parameters using SPSS 16.0 version. p>0.05 was considered as statistically significant.

\section{RESULTS AND DISCUSSION}

MNs test has been getting attention as a simple and sensitive short-term assay for the detection of environmental genotoxicity [10]. Analysis of exfoliated buccal cells provides evidence of other NAs such as BNs, KR, and KL [11].

Urbanization has led to enormous increase in number of automobiles and accordingly to increased number of petrol filling stations and workshops for repairing the vehicles. Workers engaged in these places are continuously exposed to petrol and diesel fumes. The particles generated from petrol exhaust are extremely small and are present in the nuclei or accumulation modes, with diameters of $0.02 \mathrm{~nm}$ and $0.2 \mathrm{~nm}$, respectively [12].

The occupational solvents such as benzene in petrol and diesel fumes get absorbed into the human body either through the respiratory tract or through epidermal contact [13].

Biomarkers of genotoxicity have received a considerable interest as tools for detecting human genotoxic exposure and its effects, especially in health surveillance programs dealing with chemical carcinogens. Petroleum products are a complex mixture of aliphatic and aromatic hydrocarbons with high volatility. Such types of hydrocarbons exhibit co-mutagenic and co-carcinogenic properties [14]. Benzene is one of such hydrocarbon and is the natural component of petroleum products [15]. Its content in petrol is in range of $1-5 \%$. In India, gasoline contains $3 \%$ benzene. The percentage of benzene may be as high as $30 \%$ in gasoline in some countries [16].

In the present study, we have tried to assess MN and other NAs as biomarkers of genotoxicity in AMs. In the present study, we found that frequency of MN and other NAs were significantly increased in AMs as compared to control group as shown in Table 1. Furthermore, as the year of exposure increases, frequency of MN and other NAs was significantly increased in AMs as shown in Table 2.

Our findings coincide with the findings of other authors, Khan et al. [17] and also our finding are confirm with the findings from the previous studies, which report the increased frequency of MN formation in oral buccal epithelial cells of automobile car mechanics (Sudha Sellappa), petrol pump workers (Paul et al.; Metgud et al.), and painters (Khan et al.) as compared to control [18-21].

BNs are probably indicative of failed cytokinesis following the last nuclear division in the basal cell layer [22]. KR is indicative of more extensive nuclear chromatin aggregation which leads to disintegration of the nucleus [23]. Binucleus formation is considered as indicator of cytotoxicity, while $\mathrm{KR}$ and $\mathrm{KL}$ are considered as indicators of apoptosis [21]. It has been postulated that repeated exposure to cytotoxicants can result in chronic cell injury, compensatory cell proliferation, chronic cell injury, and ultimately tumor development [24].

Increased frequency of $\mathrm{MN}$ and other NAs in our study reveal that AMs are under the risk of significant cytogenetic damage. MN assay can be regarded as an important biomarker to predict the relative risk of occurrence of cancer $[25,26]$. MN assay is rapid, easy, cheap,

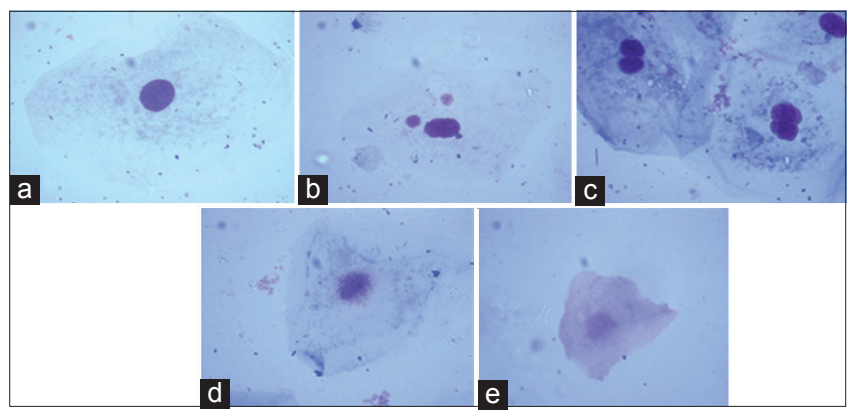

Fig. 1: (a) Normal cell, (b) micronucleate cell, (c) binucleate cell, (d) karyorrhexis, and (e) karyolysis. Micronuclei and other nuclear abnormalities in exfoliated buccal cells of automobile mechanics and in control group

Table 1: Mean \pm SD of MN and other NAs in automobile workers and control group

\begin{tabular}{lllll}
\hline Parameters & Mean \pm SD & t-test & p value \\
\cline { 2 - 3 } & $\begin{array}{l}\text { Automobile } \\
\text { workers }\end{array}$ & $\begin{array}{l}\text { Control } \\
\text { group }\end{array}$ & & \\
\hline MNC & $8.20 \pm 6.134$ & $5.10 \pm 3.722$ & 3.347 & $0.001^{*}$ \\
BNC & $13.57 \pm 7.892$ & $8.82 \pm 3.855$ & 4.189 & $0.00^{*}$ \\
KRC & $16.70 \pm 10.818$ & $12.30 \pm 5.176$ & 2.842 & $0.05^{*}$ \\
KLC & $22.10 \pm 11.685$ & $16.12 \pm 6.370$ & 3.483 & $0.01^{*}$ \\
\hline
\end{tabular}

*: Significant, MNCs: Micronucleated cells, BNCs: Binucleated cells, KRC: Karyorrhectic cell, KLCs: Karyolytic cells, SD: Standard deviation, MNs: Micronuclei, NAs: Nuclear abnormalities 
Table 2: Mean \pm SD of MN and other NAs in automobile workers according to the duration of exposure

\begin{tabular}{lllll}
\hline Parameters & Group I mean \pm SD $(\mathbf{n = 4 5 )}$ & Group II mean \pm SD $(\mathbf{n = 1 0})$ & Group III Mean \pm SD (n=5) & F \\
\hline MNC & $5.80 \pm 4.037$ & $15.30 \pm 4.596^{\mathrm{a}}$ & $15.60 \pm 8.295^{\mathrm{b}}$ & 24.996 \\
BNC & $12.49 \pm 7.710$ & $13.50 \pm 5.642$ & $23.40 \pm 7.701^{\mathrm{b}, \mathrm{c}}$ & $0.000^{*}$ \\
KRC & $15.62 \pm 10.654$ & $15.70 \pm 6.165$ & $28.40 \pm 14.328^{\mathrm{b}}$ & $0.011^{*}$ \\
KLC & $18.20 \pm 7.397$ & $29.90 \pm 11.170^{\mathrm{a}}$ & $41.60 \pm 18.243^{\mathrm{b}}$ & 3.456 \\
\hline
\end{tabular}

*: Significant. Group-I (1-5 years exposure), Group-II (6-10 years exposure), Group-III (more than 10 years exposure). MNCs: Micronucleated cells, BNCs: Binucleated cells, KRCs: Karyorrhectic cell, KLCs: Karyolytic cells. Values are expressed as mean \pm SD; ANOVA followed by Tukey HSD post hoc within group comparison tests was done. Subscript a, b, and c express the significance difference between (I and II) (I and III) (II and III). SD: Standard deviation, MN: Micronuclei, NAs: Nuclear abnormalities

and sensitive tool for the detection of mutagens [27,28]. Micronucleus test in exfoliated epithelial cells seems to be a useful biomarker of occupational exposure to genotoxic chemicals. As demonstrated in this study, other NAs, such as binucleates, KL, and KR, are also useful indices of chemical exposure and toxic response.

These AMs are not aware that they have been exposed to genotoxic agents. Therefore, there is a need to educate those mechanics, about the potential occupational hazards and the importance of using protective measures.

\section{CONCLUSION}

$\mathrm{MN}$ and other NAs reflect genetic changes and events associated with carcinogenesis so it is considered as biomarkers of genotoxicity. Therefore, the results of this study indicate that AMs exposed to PAHs are under the risk of significant cytogenetic damage. Therefore, it is important to provide and to create better awareness of occupational hazards among these workers to promote occupational safety.

\section{AUTHORS' CONTRIBUTION}

Mrs. Smita V Patil - conception and design of study and drafting of the manuscript. Dr. Mrs. Sumangala Patil - critical revision of the manuscript for important intellectual content. Dr. Mrs. Sampada Kanitkar- supervision of the study and acquisition of data.

\section{CONFLICTS OF INTEREST}

There are no conflicts of interest for the present study.

\section{REFERENCES}

1. Keshava N, Ong TM. Occupational exposure to genotoxic agents. Mutat Res 1999;437:175-94.

2. Martson CP, Pareira C, Ferguson J, Fischer K, Olaf H, Dashwood W, et al. Effect of complex environmental mixture from coal tar containing PAH on tumor initiation, PAH-DNA binding and metabolic activation of carcinogenic PAH in mouse epidermis. Carcinogenesis 2001;22:1077-85.

3. Simko P. Determination of Polycyclic aromatic hydrocarbons in smoked meat products and smoke flavouring food additives. J Chromatogr B Analyt Technol Biomed Life Sci 2002;770:3-18.

4. Fenech M, Crott JW. Micronuclei, nucleoplasmic bridges and nuclear buds induced in folic acid deficient human lymphocytes-evidence for breakage-fusion-bridge cycles in the cytokinesis-block micronucleus assay. Mutat Res 2002;504:131-6.

5. Manno M, Viau C, in collaboration with, Cocker J, Colosio C, Lowry L, et al. Biomonitoring for occupational health risk assessment (BOHRA). Toxicol Lett 2010;192:3-16.

6. Battershill JM, Burnett K, Bull S. Factors affecting the incidence of genotoxicity biomarkers in peripheral blood lymphocytes: Impact on design of biomonitoring studies. Mutagenesis 2008;23:423-37.

7. IARC. Monographs on the Evaluation of the Carcinogenic Risks to Humans. Occupational Exposures in Petroleum Re®ning: Crude Oil and Major Petroleum Fuels. Vol. 4. Lyon, France: IARC; 1989.

8. Carere A, Antoccia A, Crebelli R, Degrassi F, Fiore M, Iavarone I, et al. Genetic effects of petroleum fuels: Cytogenetic monitoring of gasoline station attendants. Mutat Res 1995:332:17-26.

9. Tolbert PE, Shy CM, Allen JW. Micronuclei and other anomalies in buccal smears: Methods development. Mutat Res 1992;271:69-77.

10. Stich HF, Stich W, Parida BB. Elevated frequency of micronucleated cells in the buccal mucosa of individuals at high risk for risk for oral cancer: Betel quid chewers. Cancer Lett 1982;17:125-34.

11. Patil Smita V, Patil S, Kanitkar S, Gaikwad P. Effect of petroleum fumes on cardio-pulmonary efficiency in petrol pump workers of Western Maharashtra. Res J Pharm Biol Chem Sci 2017;8:408-11.

12. Patil Smita V, Patil S, Kanitkar S. Study of peak expiratory flow rate as the assessment of lung function in occupationally exposed petrol pump workers of Western Maharashtra. J Krishna Inst Med Sci Univ 2016;5:95-100.

13. Celik A, Cavas T, Ergene-Goezuekara S. Cytogenetic biomonitoring in petrol station attendants: micronucleus test in exfoliated buccal cells. Mutagenesis 2003;18:417-21.

14. Infante PF, Schwartz E, Cahill R. Benzene in petrol: A continuing hazard. Lancet 1990;336:814-5.

15. Ireland B, Collins JJ, Buckley CF, Riordan SG. Cancer mortality among workers with benzene exposure. Epidemiology 1997;8:18-20.

16. Jois HS, Kale AD, Kumar MK. Micronucleus as potential biomarker of oral carcinogenesis. Indian J Dent Adv 2010;2:197-20.

17. Khan MR, Sudha S. Evaluation of genotoxicity in automobile mechanics occupationally exposed to polycyclic aromatic hydrocarbons (PAHs) by using micronuclei and other nuclear abnormalities. Iran J Cancer Prev 2012;2:87-92.

18. Sellappa S. Oxidative damage in automobile repair garage workers occupationally exposed to polycyclic aromatic hydrocarbons. J Community Med Health Educ 2013;3:4.

19. Paul S, Chakrabarty A, Deb B, Roy P. Nuclear abnormalities in exfoliated cbuccal epithelial cells of petrol pump attendents of southern Assam, India. J Glob Biosci 2016;5:3491-9.

20. Metgud R, Khajuria N, Patel S, Lerra S. Nuclear anomalies in exfoliated buccal epithelial cells of petrol station attendants in Udaipur, Rajasthan. J Can Res Ther 2015;11:868-73.

21. Khan MR, Sudha S. Elevated frequencies of micronuclei and other nuclear abnormalities in buccal epithelial cells of spray painters in South India Int J Pharm Life Sci (IJPLS) 2013;4:2680-4.

22. Vainio HM, Sorsa H. Occupational cancer. J Toxicol Environ Health 1980;6:921-1035.

23. Verma Y, Rana SV. Biological monitoring of exposure to benzene in petrol pump workers and dry cleaner. Ind Health 2001;39:330-3.

24. IARC Monographs on the Evaluation of the Carcinogenic Risks to Human. Diesel and gasoline engine exhaust and some nitroarenes. IARC Monogr Eval Carcinog Risks Hum 1989;46:1-458.

25. Bloching M, Hofmann A, Lautenschläger C, Berghaus A, Grummt T. Exfoliative cytology of normal buccal mucosa to predict the relative risk of cancer in the upper aerodigestive tract using the $\mathrm{MN}$-assay. Oral Oncol 2000;36:550-5.

26. Singaravelu SR, Sellappa S. Assessment of genotoxicity in exfoliated buccal epithelial cells of foundary workers occupationally exposed to polycyclic aromatic hydrocarbons. Asian J Pharm Clin Res 2013;6:339-42.

27. Ambasta SK, Kumari S, Sinha UK. Anticlastogenicity of Tinospora cordifolia stem extract against arsenic genotoxicity in Mus musculus bone marrow erythrocytes using micronucleus assay. Int J Pharm Pharm Sci 2017;9:260-4

28. Thiyam R, Narasu ML. Evaluation of cytotoxic and genotoxic effects of zerumbone on colon adenocarcinoma colo205 cells and human lymphocytes. Int J Pharm Pharmsci 2017:9:92-6. 